Jovani Antônio Steffani

(iD) https://orcid.org/0000-0002-0914-7434

Marisa Magali Maieski Wames ${ }^{b}$

(iD) https://orcid.org/0000-0002-2054-6217

Tuany Eichwald ${ }^{\mathrm{a}}$

(iD) http://orcid.org/0000-0001-6764-8352

Fabiana Meneghetti Dallacosta ${ }^{a}$

(iD) http://orcid.org/0000-0003-3515-9225

Carina Rossoni ${ }^{\mathrm{a}}$

(iD) https://orcid.org/0000-0002-6494-4639

Sirlei Favero Cetolin ${ }^{\mathrm{a}}$

(iD) https://orcid.org/0000-0002-2954-0815

a Universidade do Oeste de Santa Catarina (Unoesc), Programa de Pós-Graduação em Biociências e Saúde. Joaçaba, SC, Brasil.

b Instituto Nacional de Seguridade Social (INSS). Joaçaba, SC, Brasil.

Contato:

Tuany Eichwald

E-mail:

tuany.e@hotmail.com

Os autores declaram que o trabalho não foi subvencionado e que não há conflitos de interesses.

Os autores informam que o trabalho não foi apresentado em evento científico e que não foi baseado em dissertação ou tese.

\section{Ação interinstitucional e participação social na atuação da Comissão Intersetorial de Saúde do Trabalhador e da Trabalhadora: relato de caso}

\author{
Interinstitutional action and social participation in the work of \\ the Intersectoral Commission on Occupational Health: case report
}

\section{Resumo}

Objetivo: socializar as estratégias desenvolvidas pela Comissão Intersetorial de Saúde do Trabalhador e da Trabalhadora (CISTT) do município de Joaçaba/ SC, Brasil, entre os anos de 2012 e 2017. Métodos: relato de experiência com base em levantamento e análise documental de atas e relatórios da CISTT, matérias jornalísticas e sites de instituições públicas e de sindicatos. Resultados: diálogos e interação com a comunidade a respeito do tema de saúde do trabalhador (ST) por meio de promoção de seminários temáticos sobre trabalho e saúde, concurso e exposição de fotografias, concurso de redação e desenhos, publicação de livro, criação de lei municipal, implantação do sistema de Vigilância em Saúde do Trabalhador e discussão, proposição e acompanhamento de políticas públicas na área de ST. Conclusão: apesar das dificuldades e facilidades institucionais características de um município de pequeno porte, as atividades adotadas na implementação da CISTT se configuram como uma estratégia importante para a promoção da saúde no campo da ST.

Palavras-chave: participação social; Sistema Único de Saúde; vigilância em saúde; saúde do trabalhador; políticas públicas.

\begin{abstract}
Objective: to socialize the strategies developed by the Intersectoral Commission on Worker's Health (CISTT) of the municipality of Joaçaba/SC, Brazil, from 2012 to 2017. Methods: experience report based on documentary survey and analysis of CISTT's minutes and reports, newspaper articles and websites of public institutions and trade unions. Results: dialogues and interaction with the community through the promotion of thematic seminars on work and health; photo contest and exhibition; writing and drawing contest; book publishing; municipal law proposal and approval; implementation of the Occupational Health Surveillance System; discussion, proposition and monitoring of occupational health policies. Conclusion: despite the institutional difficulties and simplicities that are characteristic of small municipalities in Brazil, the activities adopted in CISTT implementation constitute an important strategy for worker's health promotion.
\end{abstract}

Keywords: social participation; Unified Health System; health surveillance; occupational health; public policies. 


\section{Introdução}

O legado social de nossa história é exibido na permanência de grandes desigualdades sociais. A participação social se contrapõe a esse fato e é de grande importância, já que pode ser atribuída como uma prática sanitária. Tem por objetivo a articulação no processo saúde-doença, compreendendo-se saúde como um direito social, influenciado por determinantes sociais, entre os quais a participação da população se mostra necessária para sua completa implementação e execução ${ }^{1,2}$.

Nessa lógica, a Constituição Federal de $1988^{3}$, por meio do artigo 200, prescreve como competência do Sistema Único de Saúde (SUS) o cuidado à saúde dos trabalhadores e, por meio do art. 198, prevê a participação da comunidade, autorizando a participação dos usuários do SUS no planejamento, no controle das práticas de atenção e até mesmo na gestão dos dispositivos institucionais ${ }^{4}$. Complementarmente, a Lei Federal $n^{\circ} 8.142$, de $1990^{5}$, que visa regulamentar os dispositivos constitucionais, orienta a operacionalização da participação social por meio da constituição dos Conselhos de Saúde nos âmbitos nacional, estadual e municipal.

O controle social na saúde é, então, um dos princípios organizativos do SUS que garante a participação da população no processo de formulação e controle das políticas de saúde no Brasil. Portanto, a administração pública deve acolher os anseios da população, para que a participação em saúde possa ocorrer de duas formas: 1. como participação institucionalizada, via Conselhos de Saúde nas três esferas de governo, conferindo-lhes a atribuição de atuar como cogestão no SUS; 2. como participação não institucionalizada, envolvendo movimentos sociais, populares, fóruns e redes sociais, por exemplo ${ }^{6-8}$.

No que tange aos Conselhos de Saúde, a Resolução $n^{\circ} 453 / 2012^{8}$ prega que eles são órgãos permanentes do SUS e que devem unificar a participação da sociedade na administração da saúde, atribuindo-lhes além do caráter permanente, o caráter deliberativo ${ }^{9}$. Observou-se que a participação popular na saúde pode ser entendida, assim, como um compartilhamento de poder entre o Estado e a sociedade $^{10}$.

Apesar dos avanços previstos nessas bases legais brasileiras, os Conselhos ainda enfrentam desafios para a sua concretização prática. A real participação popular não está completamente consolidada. Segundo a Política nacional de gestão estratégica e participativa no SUS "os Conselhos de Saúde ainda são altamente institucionalizados e favorecem uma linha de atuação que, no limite, hierarquiza e legitima as ações e resoluções do gestor” ${ }^{11}$ (p. 894).
Essa condição denota que os Conselhos apresentam vulnerabilidades, sinalizando para alguns casos em que ainda estejam apenas cumprindo como um dispositivo legal, maculando a efetiva participação social. Isso sem falar dos demais obstáculos como, por exemplo, as precárias condições de funcionamento dos Conselhos, a falta de transparência por parte da administração pública, a falta de mobilização para formular novas e atuais estratégias no novo modelo de atenção à saúde ${ }^{12}$. Igualmente problemática é a falta de conhecimento sobre a atuação dos Conselhos por parte dos usuários e dos gestores, que não conferem a devida importância a eles ${ }^{13}$, o que também é um fator que implica redução da efetividade e independência dos Conselhos de Saúde.

Mas apesar de algumas fragilidades e de os Conselhos de Saúde se constituírem em espaços em que há disputas e conflitos por conta da interação entre seus representantes com interesses diversos, distintas formações e expectativas, também é um espaço com potencialidade para fortalecimento da cidadania, favorecendo, por meio da participação positiva de seus conselheiros, a implementação do SUS nos três níveis, com destaque para o nível local ${ }^{14}$.

Como estratégia para avançar e romper com o "isolamento" sofrido pela saúde do trabalhador, foi criada em 2002 uma rede que dialoga com o SUS, a Rede Nacional de Atenção Integral à Saúde do Trabalhador (Renast), a ser implementada por meio dos Centros de Referência em Saúde do Trabalhador (Cerest). A Renast foi efetivada em municípios sentinelas, que surgiriam "para dar subsídio técnico para o SUS nas ações de promoção, prevenção, vigilância, diagnóstico, tratamento e reabilitação da saúde dos trabalhadores e trabalhadoras"15 (p. 773).

Contudo, a Renast apresenta em sua trajetória alguns impasses e obstáculos para sua efetiva implementação $0^{16}$, como a inexistência de um sistema de capacitação e informação, falta de canais de comunicação, escassez de ações de vigilância em saúde do trabalhador, baixa articulação intrassetorial, inexistência de pactos intersetoriais etc.

Portanto, embora os Conselhos de Saúde e a Renast representem avanços, é preciso fortalecer o exercício do controle social, afinal, a tendência de agravamento das precárias condições de saúde e segurança dessa população tem sido fortalecida pelo desmonte dos direitos dos trabalhadores, representado pela reforma trabalhista recentemente aprovada no país, e será ainda muito piorada haja vista a reforma previdenciária recém-aprovada. Uma das formas de controle social se dá por meio da Comissão Intersetorial de Saúde 
do Trabalhador e da Trabalhadora (CISTT), que tem a finalidade de assessoramento do Conselho Municipal de Saúde (CMS) na articulação de políticas e programas de interesse para a saúde do trabalhador e da trabalhadora.

Considerando-se que a consolidação da participação social no campo da saúde da população trabalhadora também perpassa estratégias que sejam capazes de fortalecer as esferas de controle social do SUS e, simultaneamente, avançar no aperfeiçoamento desses espaços e na criação e legitimação de novas formas de participação ${ }^{15}$, o objetivo do presente trabalho é socializar, por meio deste relato de experiência, as atividades desenvolvidas pela CISTT do município de Joaçaba/SC entre os anos de 2012 a 2017.

\section{Métodos}

Relato de experiência do controle social, neste caso representado pelo CMS do município de Joaçaba/SC, via CISTT, constituída com ampla participação intersetorial e de sindicatos representantes dos trabalhadores. A CISTT é um instrumento fundamental para a construção e implementação das ações de saúde do trabalhador e da trabalhadora, conforme mencionado nas Portarias $\mathrm{n}^{\circ} 3.120 / 1998$, $\mathrm{n}^{\circ} 3.908 / 1998, \mathrm{n}^{\circ} 1.679 / 2002, \mathrm{n}^{\circ} 2.728 / 2009$ e $\mathrm{n}^{\circ}$ 1.823/2012 do Ministério da Saúde. Conforme previsto nessas portarias, a CISTT não deve ter um regimento interno próprio, devendo seguir o regimento do CMS. O calendário das reuniões é definido pela plenária da CISTT e publicizado posteriormente para quem mais desejar participar. As pautas das reuniões são definidas pela plenária a cada reunião, de acordo com as necessidades e prioridades.

As informações para este relato de experiência foram obtidas e organizadas pelos autores a partir da análise do ordenamento jurídico que criou a CISTT do município de Joaçaba, das atas das suas reuniões, dos relatórios enviados pela comissão ao CMS, da reunião de registros feitos por meio de matérias jornalísticas, sites institucionais (do município, universidade local, Instituto Nacional do Seguro Social - agência regional, Ministério Público do Trabalho, Justiça do Trabalho, sindicatos), da análise da repercussão de eventos e de ações desenvolvidas pela comissão em meio à comunidade (seminários, concursos de desenhos, fotografias e redações - quantidade de participantes - número de escolas e demais entidades inscritas - resultados - premiações etc.) e, também, por meio da participação direta dos autores em algumas das reuniões da comissão.
A fim de caracterizar as estratégias da participação do controle social na promoção da saúde dos trabalhadores a partir da análise das ações da CISTT/CMS/Joaçaba desenvolvidas no período de 2012 a 2017, as atividades foram avaliadas buscando-se evidenciar os seus potenciais para a promoção: 1. do envolvimento e da participação intersetorial na discussão de assuntos de interesse da saúde dos trabalhadores; 2. do fortalecimento da cultura nesse sentido; e 3. da ampliação desse debate na sociedade.

\section{Resultados e discussão}

\section{A criação e composição da CISTT}

Com dificuldades para avançar na atenção à saúde dos trabalhadores e também de envolver diferentes setores (instituições) na discussão, o CMS de Joaçaba, em 2009, por desejo de seu presidente, a partir do alinhamento dos interesses nessa área com a agência regional do Instituto Nacional de Seguridade Social (INSS) do município, via Serviço Social do Instituto, priorizou a criação da CISTT que, conforme estabelecido no art. 12 da Lei $8.080 / 1990^{17}$, tem o propósito de assessorá-lo na temática de saúde do trabalhador e da trabalhadora, com a finalidade de articular políticas e programas de interesse para a saúde dessa população em especial, cuja execução envolva ou não áreas compreendidas no âmbito do SUS.

Para melhor compreensão do leitor a respeito do contexto em que a CISTT atua, é importante citar que o município de Joaçaba pertence à região meio-oeste do estado de Santa Catarina, com aproximadamente 30.000 habitantes, possui IDH de 0,827 pontos, e sua economia se baseia, principalmente, nas atividades agropecuárias e na indústria metal-mecânica ${ }^{18}$.

A presidência do CMS/Joaçaba manifestava que o controle social no sistema teria papel fundamental, seja na definição, no controle ou na fiscalização das políticas públicas de saúde. Por essa razão, entendeu que a CISTT deveria ser estrategicamente composta com o maior número possível de representantes de diversas instituições e garantir ampla representatividade dos trabalhadores usuários do sistema, o que não foi um processo muito simples, mas que, para contar com o esforço coletivo, precisava garantir a existência do coletivo.

No cenário de necessidade da existência do coletivo, considerando-se que ao SUS compete o cuidado à saúde do trabalhador, ao INSS a reabilitação nos casos de acidentes ou doenças, aos sindicatos a representação e proteção dos direitos dos trabalhadores (inclusive os relacionados à saúde), às universidades 
a pesquisa e a formação em nível superior de profissionais da saúde, do direito e correlatos que farão enfrentamentos de toda ordem na seara da saúde dos trabalhadores, ao Ministério Público do Trabalho a proteção e garantia dos direitos do coletivo de trabalhadores, ao Serviço Social da Indústria (Sesi) a promoção de ambientes seguros e saudáveis no trabalho, à Ordem dos Advogados do Brasil (OAB) a garantia dos direitos fundamentais e da ordem jurídica, não haveria ambiente mais oportuno que a CISTT para congregar todos que têm interesses que convergem em torno do tema.

Estabelecida a prioridade e reconhecida a necessidade de atuação de modo interdisciplinar e interinstitucional, foram convidadas pelo CMS inúmeras entidades representativas no município de Joaçaba. Várias entidades aderiram ao projeto de construção da CISTT ainda em 2009, participando de reuniões mensais para discutir propostas de atuação em meio à comunidade, estudando o tema e discutindo proposições para garantir a efetividade da intersetorialidade; outras aderiram à ideia posteriormente. Assim, essa CISTT foi criada pelo CMS de Joaçaba em 28 de abril de 2010, por meio da Resolução CMS $n^{\circ}$ 007, cujos membros foram nomeados por meio das resoluções CMS ${ }^{\circ}$ 004/2011 e n ${ }^{0} 10 / 2016$, e foi constituída por representantes indicados pelas instituições convidadas e também pelas demais que demonstraram interesse, além, é claro, de trabalhadores da área da saúde e dos demais segmentos, os quais estão representados majoritariamente por seus respectivos sindicatos.

Com o avanço das discussões no âmbito da CISTT recém-criada, foi ganhando força a percepção da necessidade de incorporação de um número maior de sindicatos, como forma de aumentar a representação dos trabalhadores e também de outras entidades com objetivos e metas em comum. Com as incorporações que foram sendo feitas, atualmente a composição da Comissão está representada pelas entidades indicadas na Figura 1.

De acordo com os registros contidos nas atas das reuniões ordinárias do ano de 2007, em especial a primeira, para o CMS/Joaçaba, esta forma de composição da CISTT, além de estratégica para promover o envolvimento e participação intersetorial na discussão da saúde dos trabalhadores, permitiu que a atuação da sociedade no sistema de saúde ganhasse uma nova dimensão, tendo a participação social ampliada, democratizada e passando a ser qualificada por controle social, com a população participando do planejamento das políticas públicas, fiscalizando as ações do governo, verificando o cumprimento das leis relacionadas ao SUS e analisando as aplicações financeiras realizadas pelo município ou pelo estado no gerenciamento da saúde.

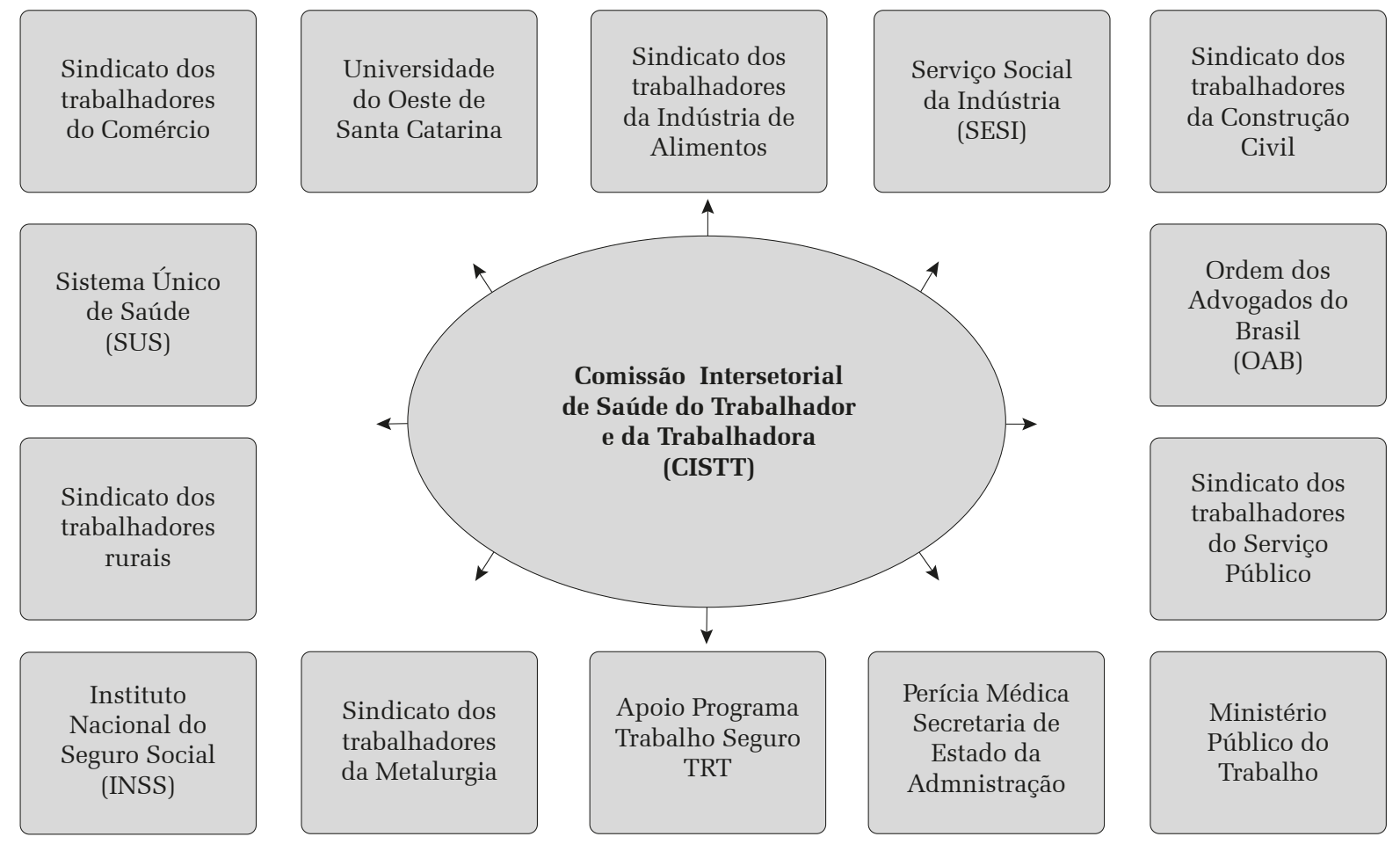

Figura 1 Representação esquemática da composição atual da Comissão Intersetorial de Saúde do Trabalhador e da Trabalhadora (CISTT) 


\section{Seminários temáticos sobre trabalho e saúde}

A primeira pauta estabelecida por essa CISTT foi dar visibilidade ao tema "Saúde do Trabalhador", levando-se em conta as estatísticas daquele momento envolvendo acidentes e mortes no trabalho, dados confirmados pelo Anuário Estatístico da Previdência Social, com base em levantamentos de 2014 a 2016, que mostraram que Santa Catarina tem a quarta maior concentração de mortes por acidentes de trabalho no país, atrás apenas de São Paulo, Paraná e Minas Gerais ${ }^{19}$. Neste sentido, com o objetivo de promover a sensibilização e o reconhecimento sobre a importância do tema por parte dos gestores/prestadores, trabalhadores, comunidade geral e usuários do SUS, a CISTT passou a realizar sistematicamente no mês de abril o "Seminário em memória às vítimas de acidentes e doenças do trabalho", considerando que 28 de abril é o Dia Mundial da Segurança e Saúde no Trabalho, estabelecido pela Organização Internacional do Trabalho.

Os primeiros três seminários foram realizados nos anos de 2012, 2013 e 2014 e envolveram diversas entidades, trabalhadores e seus representantes, estudantes do ensino superior da área da saúde, da segurança e do direito. Em todos os seminários, a programação foi construída de forma intersetorializada e interdisciplinar, e as entidades representadas bancaram o custeio dos eventos, conferindo gratuidade à participação da população.

A organização desses eventos, além de proporcionar a ampliação do debate com a sociedade com o objetivo de incitar o desenvolvimento da consciência coletiva para a problemática, se constituiu num processo que manteve e mantém quase que permanentemente a recirculação do tema na própria CISTT e com o público externo. Essa condição, podemos dizer, acabou por "forçar" as diferentes instituições presentes nessa comissão a pensar nas suas respectivas responsabilidades também, enquanto representantes do controle social, a propor soluções ou, ao menos, estratégias para o controle desses problemas, configurando-se como práticas que efetivam a participação da sociedade na gestão ${ }^{20}$.

\section{Fotografias e diálogos sobre o trabalho e saúde}

A partir do ano de 2014, como forma de inovação e incorporação de valores, percepções e ações, os seminários passaram a tratar de temáticas específicas e contaram, adicionalmente, com um concurso simultâneo de fotografias relacionadas ao tema de saúde e segurança no trabalho. Os eventos mantiveram a sua denominação genérica de "Seminário de Saúde do Trabalhador”, com a extensão de suas respectivas temáticas, as quais foram definidas a partir das demandas da realidade local.

Os concursos têm como tema transversal "O trabalho pela vida, não a vida pelo trabalho”, com o objetivo de chamar atenção para o nosso cotidiano. São passíveis de inscrição imagens originais mostrando indivíduos exercendo suas atividades de trabalho em que as situações de risco, negligência, acidentes ou adoecimento - ou mesmo o oposto, onde constem boas práticas de cuidado, proteção e prevenção que mereçam destaque - sejam evidenciadas.

Em todas as edições do concurso, os vencedores, detentores dos direitos autorais das fotografias, foram premiados e cederam gentilmente os direitos autorais das imagens à CISTT, que produziu o material e criou um acervo próprio, a partir do qual passou a realizar exposições fotográficas itinerantes em diversas instituições e espaços públicos de grande circulação de pessoas e trabalhadores, tais como bancos, bibliotecas, Prefeitura, Justiça do Trabalho, sindicatos, escolas, universidades, Sesi etc. A cada novo seminário, no hall de entrada do evento, o acervo com as fotos do concurso anterior inicia a rodada de novas exposições itinerantes.

Considerando-se que são múltiplas as instituições com interesse em proteger de alguma forma a saúde dos trabalhadores (SUS, empregadores, sindicatos, INSS, Ministério Público do Trabalho, Justiça do Trabalho, sociedades científicas, entre outras) e que cada uma atua por meio de ações particularizadas (leia-se: não articuladas com as demais), observamos que a integração de ações entre as instituições e com os diferentes segmentos da população, com o objetivo de manter as questões afetas à saúde no trabalho em foco, é uma estratégia que tem permitido manter a mobilização e articulação contínua da sociedade na defesa dos princípios que fundamentam a saúde do trabalhador, com destaque para a integração interinstitucional, que é "compreendida como o exercício da transversalidade entre as políticas de saúde do trabalhador e outras políticas setoriais, como previdência, trabalho e meio ambiente, e educação" ${ }^{21}$ (p. 3). Além disso, promove também a pluriinstitucionalidade, que se traduz na articulação entre as instâncias de vigilância em saúde do trabalhador e na "rede de atenção à saúde, universidades, centros de pesquisa e demais instituições públicas com responsabilidade na área da saúde do trabalhador, consumo e ambiente”, conforme sugere a Secretaria de Vigilância em saúde por meio das Diretrizes de implantação da Vigilância em Saúde do Trabalhador no $S U S^{21}$ (p. 3-4).

Por meio de ações como essas, a CISTT cumpre seus objetivos e finalidades, conforme descrito 
na literatura, de "propor às instituições e entidades envolvidas que, no âmbito de suas competências, atuem no sentido de eliminar ou de reduzir os riscos à Saúde do Trabalhador"; de "integrar as diversas instâncias envolvidas nas ações de Saúde do Trabalhador e da Trabalhadora em torno de um projeto comum, visando à efetivação dos princípios do SUS"; e de "contribuir para dar conhecimento à sociedade em geral da legislação em Saúde do Trabalhador e da Trabalhadora"22 (p. 860). Ainda, procura estabelecer ações de informação, educação e comunicação em saúde do trabalhador, apoiando e promovendo a educação para o controle social, estimulando a articulação e o intercâmbio entre o CMS e entidades governamentais e não governamentais, públicas e privadas.

Apoio e acompanhamento das atividades do Centro de Referência Regional em Saúde do Trabalhador

Outra iniciativa para a qual foram direcionados grandes esforços buscou viabilizar a aproximação e o acompanhamento dos serviços e ações realizadas pelo Cerest, que está sediado no município de Concórdia/SC, distante $80 \mathrm{~km}$ de Joaçaba, no sentido de unir forças na busca por soluções no campo da saúde do trabalhador e da trabalhadora. No entanto, por escassez de recursos, por desarticulação, por falta de apoio financeiro adequado, por falta de autonomia e por dificuldades de comunicação, que são as mazelas comuns à maioria dos Cerest brasileiros, não houve condições de efetivar essa ação, restando frustrada.

É importante lembrar que essas dificuldades em relação ao planejamento das ações dos Cerest, as quais essa CISTT vivenciou, não são exclusivas do campo da saúde do trabalhador. As dificuldades são semelhantes às das equipes de saúde do SUS, com repercussões importantes para a qualidade dos serviços. Essa constatação reforça a necessidade de se continuar investindo na preparação dos profissionais e de evidenciar, com maior clareza, quais são as definições e atribuições dos Cerest, viabilizando o trabalho de referência técnica no âmbito da inter-relação entre a assistência e a vigilância em saúde do trabalhador $^{23}$.

\section{Implantação do Sistema de Vigilância em Saúde do Trabalhador municipal}

A CISTT também deliberou outras pautas visando integrar os diversos cenários e atores envolvidos nas ações de saúde do trabalhador e da trabalhadora em torno de um projeto comum.
Considerando a Política Nacional de Saúde do Trabalhador e da Trabalhadora ${ }^{24}$, articulou-se em conjunto com o CMS a implantação do Sistema de Vigilância em Saúde do Trabalhador (Visat) no SUS local. Ficou compreendido pela comissão que a partir desse importante sistema seria possível cumprir as seguintes diretrizes de implementação da vigilância em saúde do trabalhador no SUS: identificar o perfil de saúde da população trabalhadora local, considerando a análise da situação de saúde para caracterizar o território, o perfil social, econômico e ambiental dessa população, com o objetivo de promover ações com capacidade de intervenção "nos fatores determinantes dos riscos e agravos à saúde da população trabalhadora, visando eliminá-los ou, na sua impossibilidade, atenuá-los e controlá-los" ${ }^{21}$ (p. 5). Assim, a partir da implantação do Visat, será possível cumprir outra diretriz que visa "avaliar o impacto das medidas adotadas para a eliminação, controle e atenuação dos fatores determinantes dos riscos e agravos à saúde"21 (p. 5), possibilitando a tomada de decisões no âmbito do SUS e dos órgãos competentes, fortalecendo as ações interinstitucionais.

Essa ação da CISTT foi compreendida como fundamental pelo fato de a Visat se pautar nos princípios do SUS, em consonância com a Promoção da Saúde e do Sistema Nacional de Vigilância em Saúde, tendo como finalidade a promoção da saúde e a redução da morbimortalidade da população trabalhadora. Portanto, a CISTT compreende a Visat como estruturante e essencial ao modelo de Atenção Integral em Saúde do Trabalhador que, segundo as Diretrizes de implantação da Vigilância em Saúde do Trabalhador no SUS, se constitui de "saberes e práticas sanitárias, articulados intra e inter setorialmente" ${ }^{21}$ (p. 3).

Considerando-se que a maioria das ações propostas demandam empenho e desejo político para a sua implantação e efetivação, haja vista que no Brasil boa parte das ações em saúde se caracterizam mais como programas de governo do que como políticas de Estado, o que significa dizer que, a cada mudança de governo, há mudança das políticas de acordo com os interesses do Executivo, uma moção de apoio à implantação do Visat foi aprovada no seminário de saúde do trabalhado e da trabalhadora em abril de $2016^{\mathrm{C}}$. Neste mesmo ano, de eleições municipais, a CISTT, em ato solene no decorrer do mês de setembro, com a presença da mídia e dos diferentes meios de comunicação local e regional, formalizou um "Termo de Compromisso" com a implantação do Visat, contendo a assinatura de "todos" os candidatos ao pleito municipal pelo

c Detalhes do evento estão disponíveis em: https://www.cacodarosa.com/noticia/11459/seminario-debateu-indices-negativos-naconstrucao-civil. Citado em 11 dez 2019. 
Poder Executivo de Joaçaba, para que firmassem o compromisso político de efetivar o Visat durante sua gestão, caso eleitos ${ }^{d}$. No decorrer do ano de 2018, com base no compromisso público assinado pelo prefeito municipal eleito naquele pleito, o Visat foi sendo estruturado no SUS local.

Foi promovido também um curso de capacitação para os membros da Comissão sobre o Visat em 2016 e, em 2017, em parceria com o SUS de Joaçaba, a CISTT promoveu o primeiro evento de capacitação para os trabalhadores do SUS, cujos trabalhos foram conduzidos pela equipe do Cerest Estadual de Florianópolis/SC.

A partir desses avanços, a CISTT passou a examinar e a monitorar as propostas em saúde do trabalhador oriundas do Executivo municipal. O monitoramento da formulação do Plano Plurianual de Saúde do município foi acompanhado e houve constante vigilância, inclusive com solicitação formal ao CMS para que exigisse que constasse dele o Visat e as demais ações e políticas de saúde do trabalhador no SUS local.

Essa forma de atuação permitiu à CISTT avaliar e analisar os projetos e planos de saúde apresentados pela Secretaria de Saúde oriundos do Executivo municipal, garantindo o foco nas ações relacionadas à saúde do trabalhador e da trabalhadora, recomendando ao pleno do Conselho de Saúde as alterações e as complementações que se fizeram necessárias, preocupando-se, também, com a garantia da alocação de recursos financeiros, sob pena de naufragarem as boas intenções no momento de suas implantações. Essas ações de vigilância em saúde do trabalhador estão em consonância com a proposta do Ministério da Saúde ${ }^{21}$ pelo caráter proponente de mudanças e de regulação dos processos de trabalho, a partir das análises epidemiológicas, tecnológicas e sociais em uma ação múltipla e interinstitucional.

Ação conjunta com o Poder Legislativo municipal: atividades de educação permanente

"Embora esteja prevista na lei, a participação social é um processo em permanente construção, que comporta avanços e recuos e, por muitas vezes, depende de ampla mobilização da comunidade na defesa de seus direitos" 25 (p. 143). Com a CISTT/CMS/Joaçaba, esse embate não foi diferente. Foram inúmeras as barreiras impostas; porém, com a ampla mobilização em conjunto com a comunidade, com o reforço da participação de alguns vereadores defensores da causa, pela militância do presidente do CMS e pela força que o coletivo da CISTT vem representando, a resistência foi sendo desconstruída, e a força coletiva e representativa foi exitosa nas inúmeras ações propostas.

Por meio de um projeto de lei e com o apoio de alguns vereadores, a CISTT conseguiu a aprovação da Lei Municipal $\mathrm{n}^{\circ}$ 5.076, de 6 de abril de $2017^{26}$, que institui a campanha de prevenção aos acidentes de trabalho e doenças ocupacionais, denominada "Lei do Abril Verde". A campanha de prevenção do Abril Verde passa, então, a ser promovida anualmente durante o mês de abril, integra agora o calendário oficial de datas e eventos oficiais do município e tem como objetivo sensibilizar a população, promovendo a educação permanente quanto à importância da prevenção dos acidentes de trabalho e doenças ocupacionais. Desta forma, o Abril Verde passou a ser uma campanha de responsabilidade do município, com a garantia da participação e da fiscalização direta da sociedade civil no processo.

Muito embora esse processo não tenha sido fácil ou simples, a conquista dessa ação satisfaz o caráter transformador previsto nas Diretrizes de implantação da Vigilância em Saúde do Trabalhador no SUS ${ }^{21}$, que pressupõe a implantação e manutenção de processo pedagógico permanente e que requer a participação dos sujeitos.

Isto implica em assumir compromisso ético em busca da melhoria dos ambientes e processos de trabalho, com ações que contenham caráter proponente de mudanças, de intervenção e de regulação sobre os fatores determinantes dos problemas de saúde relacionados ao trabalho ${ }^{21}$ (p. 5).

Como inovação, e também cumprindo a sua função de contribuir para a promoção da sensibilização e da educação permanente, no ano de 2017 a CISTT realizou o seu primeiro Concurso de Desenho e Redação ${ }^{\mathrm{e}}$. Foi possível direcionar o debate a respeito da saúde do trabalhador para outro público, envolvendo familiares, crianças, adolescentes e jovens, estudantes das escolas públicas dos municípios de Joaçaba, Herval D’Oeste e Luzerna, e do curso técnico em Segurança do Trabalho do Instituto Federal Catarinense. A categoria de desenhos ficou restrita às crianças do $1^{\circ}$ ao $5^{\circ}$ ano do ensino fundamental, e as redações aos demais.

A intenção da CISST foi ampliar o debate com a comunidade, o qual perdurou por pelo menos oito meses, circulando nas redes sociais, escolas, mídias e sociedade em geral. Além disso, também se buscou "implantar um embrião" da cultura em segurança

d Detalhes da iniciativa estão disponíveis em: https://www.ederluiz.com.vc/candidatos-a-prefeito-de-joacaba-assinam-mocao-ese-comprometem-a-instituir-o-visat. Citado em $11 \mathrm{dez} 2019$.

e Detalhes sobre o concurso estão disponíveis em: https://www.cacodarosa.com/noticia/15696/vencedores-do-concurso-dedesenho-e-redacao-trabalho-seguro. Citado em $11 \mathrm{dez} 2019$. 
e saúde do trabalhador nas novas gerações de cidadãos(ãs) e trabalhadores(as). O referido concurso, conforme respectivo edital, teve como objetivo desenvolver ações educativas relacionadas às condições de trabalho no que diz respeito a saúde, segurança e ambiente de trabalho e difundir informações para contribuir com a proteção e promoção da saúde do trabalhador.

O evento surpreendeu pela grande adesão do público e pela qualidade dos trabalhos que trataram do tema com a atenção que ele merece. A premiação do concurso incluiu a entrega de tablets e aparelhos smartphones, que foram doados à CISTT por meio de parceria estabelecida com a Receita Federal do Brasil. Participaram mais de mil estudantes e, a partir das redações e dos desenhos premiados, foi possível criar um ebook ${ }^{27}$, como incentivo aos alunos a se tornarem autores e produtores de conteúdo em saúde e segurança dos trabalhadores e trabalhadoras, além de se configurar como uma forma de registro e organização do rico conteúdo produzido. O lançamento oficial do ebook contou com a presença de autoridades, trabalhadores, pais, alunos e sociedade civil em ato solene, voltando a fomentar a discussão em torno do tema e levando o material e o assunto para dentro das escolas.

\section{Participação democrática e intersetorial como diferencial}

Por fim, destaca-se que talvez o grande diferencial dessa CISTT seja a sua configuração, que privilegia a intersetorialidade e a representatividade dos trabalhadores por meio dos inúmeros sindicatos, condição que fomenta e permite às diferentes instituições participantes conjugarem forças para propor ações que, de modo isolado nos seus âmbitos de atuação, não seriam capazes de incorporar e de tornar realidade. Assim, com a conjugação dos conhecimentos, das competências e das ações do INSS, sindicatos, universidade, SUS, OAB, Sesi, Secretaria de Estado de Administração, Ministério Público do Trabalho, com o apoio do Programa Trabalho Seguro do Tribunal Regional do Trabalho, surgem proposições mais eficazes para o encaminhamento das diferentes e complexas demandas necessárias ao efetivo estabelecimento de ações de proteção da saúde da população trabalhadora.

O Brasil é um país de muitas iniquidades em que, apesar de ter passado por importantes avanços em sua história recente, inclusive na saúde, e apesar de o seu arcabouço jurídico promover e incentivar a participação social na gestão pública, o que se observa, segundo a própria literatura, é que o controle social não está efetivado em sua plenitude por inúmeras razões, entre as quais "a falta de informação, a existência de interesses múltiplos para que a população não saiba que possui direitos e que pode exigi-los", motivo pelo qual se deve "instituir e proporcionar condições para que a democracia participativa se efetive na prática e que a sociedade civil se torne protagonista nesse processo de controle social em políticas públicas de saúde" 25 (p. 145), pleiteando a construção de um Brasil mais justo e igualitário, sendo essa a lógica que vem desafiando e motivando a nossa CISTT.

\section{Considerações finais}

As atividades desenvolvidas por essa CISTT se configuram como uma estratégia importante para a promoção da saúde no campo da saúde dos trabalhadores, resultante da participação/controle social. Sem dúvidas, essa é uma experiência de intervenção em saúde do trabalhador que vem logrando êxito e permitindo importantes avanços no município de Joaçaba, principalmente na consolidação dos objetivos previstos pela Política Nacional de Saúde do Trabalhador e da Trabalhadora, e que pode ser replicada em outros municípios brasileiros.

Destacamos aqui a facilidade na implementação das ações da CISTT, por estar sediada em um município de pequeno porte que permite maior interação interinstitucional, tanto pela proximidade física das instituições quanto pela proximidade de convívio social de seus gestores (públicos ou privados), bem como por acessos mais amplos e facilitados aos poderes Executivo e Legislativo municipais. A principal dificuldade da CISTT se caracterizou pela falta de suporte e apoio da gestão municipal na manutenção da estrutura funcional do CMS/CISTT, representado pela falta de providência de local adequado para as reuniões, disponibilização de secretária e serviços de secretaria, de materiais de consumo, de acesso a algumas informações e de custeio de alguns gastos financeiros fundamentais no processo, mas isso foi superado por meio da contribuição direta das diversas instituições envolvidas. Outro fator limitador importante é o fato de que os membros da CISTT não dispõem de "tempo" adicional ou redução de suas tarefas nos seus locais de trabalho como forma de compensação pelo trabalho adicional na comissão. Por essa razão, as suas participações acabam se caracterizando como uma forma altruísta de colaboração pessoal com a sociedade, mas que representa sobrecarga em vários momentos da vida profissional de cada um.

A constituição da CISTT, com ampla representatividade interinstitucional e dos trabalhadores, se demonstrou como uma importante estratégia capaz de facilitar o alcance dos seguintes objetivos e finalidades previstos pelo Ministério da Saúde para as CISTT: 
- articular políticas e programas de interesse para a Saúde do Trabalhador e da Trabalhadora, cuja execução envolva áreas compreendidas e não compreendidas no âmbito do SUS;

- propor às instituições e entidades envolvidas que, no âmbito de suas competências, atuem no sentido de eliminar ou reduzir os riscos à Saúde do Trabalhador e da Trabalhadora;

- propor e acompanhar a implantação de medidas que objetivem a melhoria dos serviços de Saúde do Trabalhador e da Trabalhadora, nos setores público e privado;

- integrar as diversas instâncias envolvidas nas ações de Saúde do Trabalhador e da Trabalhadora em torno de um projeto comum, visando à efetivação dos princípios do SUS;
- acompanhar a implantação/implementação dos projetos e planos de saúde, recomendando ao Conselho de Saúde que fiscalize;

- contribuir para a promoção da sensibilização e educação permanente dos gestores/prestadores, trabalhadores e usuários do SUS sobre a importância da discussão sobre Saúde do Trabalhador e da Trabalhadora; e

- contribuir para dar conhecimento à sociedade em geral da legislação em Saúde do Trabalhador e da Trabalhadora ${ }^{28}$ (p. 10).

Ademais, esse modelo de composição da CISTT favoreceu muito o processo de comunicação entre todos os envolvidos e promoveu ambiência mais favorável e facilitadora à tomada de decisões no âmbito do coletivo intersetorial.

\section{Contribuições de autoria}

Steffani JA e Wames MMM contribuíram no levantamento das informações. Todos os autores contribuíram igualmente na elaboração, revisão e aprovação da versão final publicada e assumem responsabilidade pública pelo seu conteúdo.

\section{Referências}

1. Campos L, Wendhausen A. Participação em saúde: concepções e práticas de trabalhadores de uma equipe da Estratégia de Saúde da Família. Texto Contexto Enferm. 2007;16(2):271-9.

2. Escorel S. Reviravolta na Saúde: origem e articulação do movimento sanitário. Rio de Janeiro: Ed. Fiocruz; 1999.

3. Brasil. Constituição da República Federativa do Brasil: texto constitucional promulgado em 5 de outubro de 1988, com as alterações adotadas pelas Emendas Constitucionais nos 1/1992 a 68/2011, pelo Decreto Legislativo no 186/2008 e pelas Emendas Constitucionais de Revisão nos 1 a 6/1994. Brasília, DF: 2012.

4. Brasil. Gestão participativa e cogestão [Internet]. Brasília, DF: Ministério da Saúde; 2009 [citado em 10 abr 2019]. Disponível em: http://bvsms. saude.gov.br/bvs/publicacoes/gestao_participativa_ cogestao.pdf

5. Brasil. Lei $n^{\circ}$ 8.142, de 28 de dezembro de 1990. Dispõe sobre a participação da comunidade na gestão do Sistema Único de Saúde (SUS) e sobre as transferências intergovernamentais de recursos financeiros na área de saúde e dá outras providências. Diário Oficial da União [Internet]. 30 dez. 1990 [citado em 10 abr 2018]. Disponível em: http://conselho.saude.gov.br/legislacao/ lei8142_281290.htm

6. Arantes CIS, Mesquita CC, Machado MLT, Ogata MN. O controle social no Sistema Único de Saúde: concepções e ações de enfermeiras da atenção básica. Texto Contexto Enferm. 2007;16(3):470-8.
7. Brasil. O SUS no seu município: garantindo saúde para todos. Brasília, DF: Ministério da Saúde; 2004.

8. Brasil. Resolução n ${ }^{\circ} 453 / 2012$ do Conselho Nacional de Saúde. Aprova diretrizes para criação, reformulação, estruturação e funcionamento dos conselhos de saúde. Diário Oficial da União. 2012;(109):138.

9. Gomes ACS, Bernardo GN, Carvalho FR, Oliveira LDC, Lima TS, Mendes MM. O papel das ouvidorias e dos conselhos de saúde no SUS: uma revisão integrativa de literatura. Rev Eletronica Gest Saude. 2017;8(1):140-61.

10. Duarte EB, Machado MFAS. O exercício do controle social no âmbito do Conselho Municipal de Saúde de Canindé, CE. Saude Soc. 2012;21(supl. 1):126-37.

11. Durán PRF, Gerschman S. Desafios da participação social nos conselhos de saúde. Saude Soc. 2014;23(3):884-96.

12. Correia MVC. Desafios para o controle social: subsídios para a capacitação de conselheiros de saúde. Rio de Janeiro: Ed. Fiocruz; 2005.

13. Hoefel MG, Dias EC, Silva JM. A atenção à saúde do trabalhador no SUS: a proposta de constituição da Renast. In: Brasil. $3^{\text {a }}$ Conferência Nacional de Saúde do Trabalhador: $3^{\text {a }}$ CNST: "trabalhar, sim! adoecer não!”: coletânea de textos. Brasília, DF: Ministério da Saúde; 2005. p. 72-78.

14. Vanderlei MIG, Witt RR. Conselhos de saúde: espaços de participação social no Sistema Único de Saúde: concepções e ações de enfermeiras da atenção básica. Saude Debate. 2003;27(64):131-7. 
15. Leão LHC, Castro AC. Políticas públicas de saúde do trabalhador: análise da implantação de dispositivos de institucionalização em uma cidade brasileira. Cienc Saude Colet [Internet]. 2013 [citado em 02 abr 2018];18(3):769-78. Disponível em: http://www.scielo.br/scielo.php?script=sci arttext\&pid =S1413-81232013000300023\&lng =en

16. Brasil. Para entender o controle social na saúde. Brasília, DF: Ministério da Saúde; 2014.

17. Brasil. Lei $\mathrm{n}^{\circ}$ 8.080, de 19 de setembro de 1990. Lei Orgânica da Saúde. Dispõe sobre as condições para a promoção, proteção e recuperação da saúde, a organização e o funcionamento dos serviços correspondentes e dá outras providências. Diário Oficial da União. 20 set 1990:18055.

18. Programa das Nações Unidas para o Desenvolvimento. Atlas do Desenvolvimento Humano no Brasil [Internet]. Brasília, DF: PNUD, 2013 [citado em 15 abr 2018]. Disponível em: http://www.atlasbrasil.org.br/2013/pt/o_atlas/o_ atlas_/

19. Brasil. Ministério da Previdência Social. Anuário Estatístico da Previdência Social 2017 [Internet]. Brasília, DF: Ministério da Fazenda; 2017. Disponível em: http://sa.previdencia.gov.br/ site/2019/04/AEPS-2017-abril.pdf

20. Guizardi FL, Pinheiro R, Mattos RA, Santana AD, Matta D, Gomes MCPA. Participação da comunidade em espaços públicos de saúde: uma análise das conferências nacionais de saúde. Physis. 2004;14(1):15-39.

21. Brasil. Diretrizes de implantação da Vigilância em Saúde do Trabalhador no SUS [Internet]. Brasília, DF: Ministério da Saúde; 2014 [citado em 5 maio 2018]. Disponível em: https://renastonline.ensp. fiocruz.br/sites/default/files/arquivos/recursos/ Diretrizes-de-implantacao-da-Vigilancia-em-Saudedo-Trabalhador-no-SUS.pdf

22. Artur K. Participação e direito à saúde dos trabalhadores. Saude Soc [Internet]. 2015 [citado em 13 nov 2019];24(3):853-68. Disponível em: http://www.scielo.br/scielo.php?script=sci arttext\&pid $=$ S0104-12902015000300853\&lng $=$ en $\& n r m=$ iso

23. Dias EC, Chiavegatto CV, Silva TL, Reis JC, Silva JM. Construção da Renast em Minas Gerais: a contribuição dos Centros de Referência em Saúde do Trabalhador (Cerest), 2002-2007. Rev Med Minas Gerais. 2010;20(2 Supl. 2):S66-74.

24. Brasil. Portaria $n^{0} 1.823$, de 23 de agosto de 2012. Institui a Política Nacional de Saúde do Trabalhador e da Trabalhadora. Diário Oficial da União [Internet]. 24 ago 2012 [citado em 9 jun 2018];1;46-51. Disponível em: http:// bvsms.saude.gov.br/bvs/saudelegis/gm/2012/ prt1823_23_08_2012.html

25. Rolim LB, Cruz RSBLC, Sampaio KJAJ. Participação popular e o controle social como diretriz do SUS: uma revisão narrativa. Saude Debate. 2013;37(96):139-47.

26. Joaçaba. Lei $\mathrm{n}^{\circ} 5.076$, de 6 de abril de 2017. Institui a Campanha de Prevenção aos Acidentes do Trabalho e Doenças Ocupacionais, denominada Abril Verde, no âmbito do município de Joaçaba/SC. Diário Oficial dos Municípios de Santa Catarina [Internet]. 5 maio 2017 [citado em 10 dez 2019]. Disponível em: https:// www.diariomunicipal.sc.gov.br/site/?r=site/ acervoView\&id $=1253566$

27. Steffani JA, Wames MMM. O trabalho intersetorial que está dando certo [Internet]. Joaçaba: Ed. Unoesc; 2017 [citado em 10 dez 2019]. Disponível em: https://www.unoesc.edu.br/images/uploads/ editora/o_trabalho_intersetorial_que.pdf

28. Brasil. Conheça a CISTT: Comissão Intersetorial de Saúde do Trabalhador e da Trabalhadora [Internet]. Brasília, DF: Ministério da Saúde, 2017 [citado em 10 dez 2019]. Disponível em: http://conselho.saude.gov.br/biblioteca/ livros/11nov18_Cartilha_CNS_CISTT_Revisada_ para_NET.pdf 